TI 2019-001/VIII

Tinbergen Institute Discussion Paper
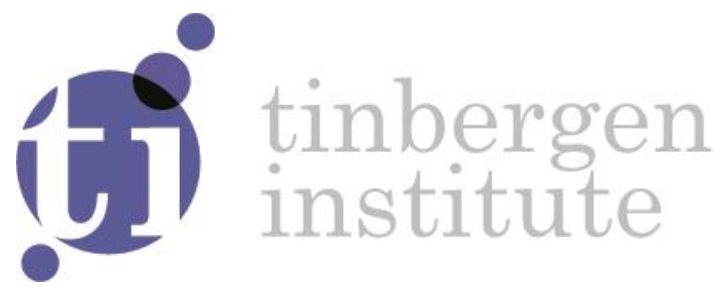

\title{
KEEPING IN TOUCH WITH \\ CITIZENS ONLINE: SOCIAL MEDIA \\ USAGE IN DUTCH LOCAL \\ GOVERNMENT
}

Bram Faber ${ }^{1}$

Tjerk Budding ${ }^{1}$

Raymond (R.H.J.M.) Gradus ${ }^{1}$

${ }^{1}$ VU Amsterdam, The Netherlands 
Tinbergen Institute is the graduate school and research institute in economics of Erasmus University Rotterdam, the University of Amsterdam and VU University Amsterdam.

Contact: discussionpapers@tinbergen.nl

More TI discussion papers can be downloaded at http://www.tinbergen.nl

Tinbergen Institute has two locations:

Tinbergen Institute Amsterdam

Gustav Mahlerplein 117

1082 MS Amsterdam

The Netherlands

Tel.: +31(0)205984580

Tinbergen Institute Rotterdam

Burg. Oudlaan 50

3062 PA Rotterdam

The Netherlands

Tel.: +31(0)10408 8900 


\section{KEEPING IN TOUCH WITH CITIZENS ONLINE:}

\section{SOCIAL MEDIA USAGE IN DUTCH LOCAL GOVERNMENT}

\section{A. S. C. (Bram) Faber*}

Vrije Universiteit Amsterdam, School of Business and Economics, De Boelelaan 1105, room 6A-59, 1081 HV Amsterdam, The Netherlands, Tel. +31 2059831 33, E-mail:

a.s.c.faber@vu.nl

\section{G. T. (Tjerk) Budding}

Vrije Universiteit Amsterdam, School of Business and Economics. E-mail: g.budding@vu.nl

\section{R. H. J. M. (Raymond) Gradus}

Vrije Universiteit Amsterdam and Tinbergen Institute, School of Business and Economics. Email: r.h.j.m.gradus@vu.nl

* Corresponding author 
Abstract: In recent years, social media has become a major venue for the interplay between citizens and public sector organizations, in order to facilitate corporate dialog. However, not much comprehensive research has been done on how interactivity between local governments and citizens takes shape. Building on earlier work that addresses municipal e-government adoption, this article does empirical work on the ways in which social media is used by all 380 Dutch municipalities. It focuses on social media usage by means of a quantitative assessment through five social media platforms: Twitter, Facebook, LinkedIn, YouTube, and Instagram. In doing so, it sheds light on the interrelations between e-government adoption, social media deployment, and sophistication of use from a local government perspective. Furthermore we identify determinants for the types of social media usage by means of a stages of an e-government model consisting of three phases. We find that more densely populated municipalities with a larger and a higher-educated population use their Twitter account significantly different from their counterparts.

Keywords: social media, municipalities, E-government, usage of Twitter-account JEL-code: D85

\section{Introduction}

E-government has been heralded as one of the reforms to promote efficiency and responsiveness (Dunleavy, Margetts, Bastow, \& Tinkler, 2005). Its general discussion is characterized by two important implications: (1) it has an impact on the efficiency of internal processes, and (2) it transforms the relationship between government and society. There has been a growing academic interest particularly for the latter implication. 
In recent years, social media has become a major venue for the interplay between citizens and public sector organizations, and its use has been growing steadily (Bertot, Jaeger, \& Grimes, 2010; Grimmelikhuijsen \& Meijer, 2015; Sandoval-Almazán \& Kavanaugh, 2018). Public sector deployment of social media has mostly been studied in relation to the democratic goals of transparency, participation, and collaboration (Bertot, Jaeger, \& Grimes, 2010; Bonsón, Torres, Royo, \& Flores, 2012; Harrison et al. 2012; Mergel, 2013).

Budding, Faber, \& Gradus (2018) showed that based on 2014-2016 panel-data for all Dutch municipalities, there is a large variety among the municipalities in the extent to which they offer their services delivery digitally. Different explanations for the variance in e-government adoption were sought by looking at socio-economic variables. Most notably was a strong relationship of so-called e-government adoption with demographic characteristics such as population, population density, and age groups. This article builds on these findings. We look at the variety in e-government adoption and sophistication by Dutch municipalities by means of the way they use social media, in order to facilitate corporate dialog (Bonsón \& Flores, 2011; Bónson, Torres, Royo, \& Flores, 2012).

This article is structured as follows. After an review of relevant literature and research context, our collection of data is discussed. In addition, we posit our adaptation of Lee \& Kwak's (2012) Open Government Maturity Model, which is used in the subsequent data analysis. The analysis consists of two parts: (1) an overview of the usage by municipalities of relevant social media, and (2) an assessment of the relationship between the adoption of egovernment through social media and a range of socio-economic and institutional variables. The discussion and conclusion section elaborate on the findings of this assessment and suggests options for future research. 


\section{Theory}

A guiding principle of e-government has been that of dividing and modelling e-government evolution into sequential steps or 'stages of growth'-models (Layne \& Lee, 2001; Valdés et al. 2011). Such models have been developed frequently, with various foci such as customercentricity (Andersen \& Henriksen, 2006) and interoperability (Gottschalk, 2009). A relevant factor in more recently developed stages models is the 'reciprocal' side of e-government: the level of interaction between organizations and citizens (Lee \& Kwak, 2012; Linders, 2012).

Social media (SM) is an important term in the perspective of the reciprocal side of egovernment. It is often used broadly; Zheng \& Zheng (2014) discern that it is used for services and technologies as varied as blogs, microblogs, sharing services, text messaging, discussion forums, collaborative editing, virtual worlds, and social networking services. Additionally Kaplan \& Haenlein (2010) define SM as a social structure in which technology puts power in communities rather than in institutions, next to a set of open, web-based and user-friendly applications that enable users to network, share data, collaborate and coproduce content. It could be argued that the definitions of SM have come to supplant the definitions of 'Web 2.0', as it was widely used up until the early 2010s (e.g., Chun, Shulman, Sandoval, \& Hovy, 2010; Molinari \& Ferro, 2009), and as it occasionally still does appear (e.g., Bonsón, Torres, Royo, \& Flores, 2012; Lidén \& Larsson, 2016).

SM has become a major venue for citizens to express their opinions and provide feedback on policies and (public) services (Bertot, Jaeger, \& Grimes, 2010; Grimmelikhuijsen \& Meijer, 2015). The use of SM by public sector organizations has been growing steadily, encouraging transformations in organization, costs, citizen interaction and efficiency (Sandoval-Almazán 
\& Kavanaugh, 2018). In accordance, SM usage by governments has become more and more a professionalized activity (Klang \& Nolin, 2011; Mergel, 2016).

A relevant concept is that of corporate dialog (Bonsón \& Flores, 2011; Bónson, Torres, Royo, \& Flores, 2012). This comprises that organizations are able to take advantage of the evolution of the web's capacities, which enables them (1) to provide more detailed and useful information, and (2) to allow users to participate through the use of new platforms. As such, corporate dialog sidelines the model of unidirectional communication from an organization to the user, and facilitates multidirectional flows between an organization and its stakeholders (Bonsón \& Flores, 2011). Additionally, Bónson, Torres, Royo, \& Flores (2012) define corporate dialog as the sum of collaboration and engagement. Collaboration is shaped by interactions between an organization and its stakeholders, and engagement through an implicit set of mutually beneficial outcomes. The deployment of SM is considered an important part of present-day corporate dialog for public organizations.

Liu \& Kim (2018) observed that SM use is still a primary concern for scholars and policymakers. They observed a notable boom of the subject in publications on the subject in the early 2010s. A range of key articles originate from this period, in which the challenges of SM for the public sector were exposed (e.g., Bertot, Jaeger, \& Grimes, 2010; Bertot, Jaeger, \& Hansen, 2012; Bonsón, Torres, Royo, \& Flores, 2012; Harrison et al. 2012; Mergel, 2013). Most of this literature has studied public sector deployment of SM in relation to democratic goals of transparency, participation, and collaboration. However, significantly less work has been done on the interactivity between local governments and citizens itself (for exceptions, see e.g., Mossberger, Wu, \& Crawford, 2013). 
In addition, most research focuses on the What-question of SM usage: what type of content do public sector organizations share through SM platforms (e.g., Bellström, Magnusson, Pettersson, \& Thorén 2016; Bonsón, Royo, \& Ratkai, 2014; 2015; Lidén \& Larsson, 2016). A considerably less amount addresses the How-question: how does communication with citizens through SM take place, and what shape does the interaction take (for exceptions, see e.g., Gao \& Lee, 2017; Hofmann, Beverungen, Räckers, \& Becker, 2013)? Empirical studies in the private sector regarding the How-question do exist (see e.g. Von Hoffen, Hagge, Betzing, \& Chasin, 2018) and are prominent in a few (semi-)public disciplines such as health care (see e.g., Benetoli, Chen, Schaefer, Chaar, \& Aslani, 2017; Chang, Yuan, \& Li, 2009; Grajales III, Sheps, Ho, Novak-Lauscher, \& Eysenbach, 2014). This calls for more empirical research on this type of social media usage in local governments. Finally, most research into e-government adoption and social media usage suffers from a small, non-comprehensive sample that does not cover an entire country (for exceptions, see e.g., Lidén \& Larsson, 2016).

This article aims to add to the existing literature by means of a comprehensive assessment of the How-question of local social media adoption and sophistication. It focuses on SM usage by means of a quantitative assessment of all 380 municipalities in the Netherlands through a range of SM platforms. In doing so, it sheds light on the interrelations between e-government adoption, SM deployment, and sophistication of use in a local government context.

\section{Research context}

The Netherlands has three layers of government: central government, province, and municipalities. The latter form the most visible layer of government. In 2018, there were 380 
municipalities. They perform tasks that could be considered the most direct forms of service delivery, such as physical planning, garbage and recyclables collection, and the issuance of passports and driver licenses. The Dutch central government has prescribed a large number of tasks that have to be performed by the local layer of government, but it is largely at the municipalities' discretion how they wish to perform these tasks. This allows for a great variety of praxis, which is adapted and tailored to every separate local context.

According to the most recent data, $97 \%$ of Dutch inhabitants have access to (high-speed) Internet (Statistics Netherlands, 2017). This puts the Netherlands among the countries with the highest Internet penetration in Europe. Also with regard to SM usage, Dutch citizens are quite active: a recent survey showed that $83 \%$ of Dutch adults over 16 years old make use of used WhatsApp, 78\% were on Facebook, 58\% made use of YouTube, 32\% used LinkedIn, $30 \%$ used Instagram, 20\% used Twitter, and 17\% used Snapchat (Newcom Research \& Consultancy, 2018). ${ }^{1}$

\footnotetext{
${ }^{1}$ Newcom Research \& Consultancy (2018) measured the actual usage of the SM platform; it did not measure if respondents have an account on the platform. Respondents were asked if they accessed the platform in the preceding six months. For some platforms, such as YouTube, an account is no requirement for actual usage, i.e..
} 


\section{Material and method}

All of the data used for this article was collected between January - May 2018. The analysis of the use that Dutch local governments make of SM tools was carried out in two steps. Data for all SM accounts were collected manually. In order to obtain reliable data, it had to be verified that the municipality itself operated the account on the SM platform in question. This was done by looking for hyperlinks in the municipal website that would redirect to an official account on the respective platform, and otherwise look if the account has a 'verified' vignette in its social medium profile. The second part of the data collection formed the in-depth analysis of Twitter accounts. The application Foller.me (Kovshenin, 2018) was used for collecting the detailed data. This application gathers the requested user's profile and 100 latest tweets, and shows a list of information accordingly. For the purpose of the regressions, all socioeconomic variables were retrieved through the portals of Statistics Netherlands and waarstaatjegemeente.nl (VNG Realisatie, 2018). Information regarding whether municipalities participated in the innovation program Vensters voor Bedrijfsvoering was collected straight from the website of this program.

'Longevity' in this article expresses the amount of days an account has been active, compared to the very first account registration of a municipality on the platform. These data were only retrievable for the platforms of Twitter and YouTube. With respect to websites, longevity data was collected by entering the name of every municipal website into the database of the 
Netherlands Foundation for Internet Domains, which keeps a retrievable registry of all Dutch websites, including the date of registration. ${ }^{2}$

As mentioned before, e-government literature addressing the degree of adaptation by public organizations is characterized by an abundance of stages models. For this article, we chose one of these models as a point of departure: the Open Government Maturity Model of Lee \& Kwak (2012), which is based on their studies with U. S. federal health care administration agencies. This stages model was considered suitable for our setting, as it takes into account the 'reciprocal' side of e-government. They distinguish five categories: (1) Initial Conditions, (2) Data Transparency, (3) Open Participation, (4) Open Collaboration, And (5) Ubiquitous Engagement. For this article, we reduced their framework by clustering it into to three distinct stages: ${ }^{3}$

1. Initial conditions. This stage is characterized by primarily cataloguing and broadcasting information and lacks interactive communication capabilities. Service

\footnotetext{
${ }^{2}$ For Twitter, the first registered account was the municipality of Almere in March 2008; for YouTube, this was the municipality of Houten in November 2006. The municipality of Amsterdam registered the first municipal website on 25 January 1994.

${ }^{3}$ Lee \& Kwak's Framework was clustered by merging the separate stages (2) Data Transparency and (3) Open Participation into the Transitional Phase, and the stages (4) Open Collaboration and (5) Ubiquitous Engagement into ubiquitous engagement
} 
delivery is mostly dealt with on the individual levels and a coherent strategy does not exist.

2. Transitional phase. This stage shows a greater willingness to receiving and interacting rather than just sending and broadcasting, however the latter is still considered its point of departure.

3. Ubiquitous engagement. This stage expands the scope and depth of e-government in service delivery perspective, integrating SM and related technologies into a more comprehensive approach.

This framework will be used and elaborated in the following sections. First we provide an overall view of SM usage by all 380 Dutch municipalities, partially following the analysis of Bonsón, Torres, Royo, \& Flores (2012). After this, we conjoin the sophistication of SM usage and the determinants for e-government adoption with our tripartite framework. We do this by developing an argument in which we link the Twitter data for municipalities to our stages model. After this, we identify socio-economic and institutional factors determining the elaborated sophistication of SM usage, and subsequently we formulate a regression model.

\section{Analysis}

This analysis starts with an overall view of SM usage by all 380 Dutch municipalities. After this, we have a closer look at social media sophistication by means of detailed Twitter data, linking this to the stages of e-government model elaborated in the previous section. This section ends with a regression model which identifies socio-economic and institutional determinants of e-government adoption and sophistication for Dutch local governments. 


\subsection{Activity on SM platforms by Dutch local governments}

We use the same starting point as Bonsón, Torres, Royo, \& Flores (2012). Their goal was, among others, to provide an overall view of SM usage in local governments of European Union member states. We look specifically at the SM platforms that are said to be used most frequently by Dutch citizens ( $c f$. Newcom Research \& Consultancy, 2018): Twitter, Facebook, LinkedIn, YouTube, Instagram, WhatsApp, and Snapchat. Table 1 shows the results of our assessment of the degree of penetration on these platforms among Dutch municipalities.

*** Please insert Table 1 about here $* * *$

Twitter is the most extensively used SM platform by Dutch municipalities: only two municipalities were found that did not have an account. It is followed closely by Facebook and LinkedIn, on which $97 \%$ of municipalities have an organizational account. Municipal accounts on YouTube are less common, but still considerable with a presence of $89 \%$. The same counts for Instagram, where for $67 \%$ of all municipalities an account could be retraced. Only $37 \%$ of the municipalities mentioned usage of WhatsApp. A reason for this could be that up until recently, WhatsApp's terms of service prescribed that the medium was explicitly intended for individual use and not for business (Hartholt, 2017). As of 2018, the terms of service were adjusted, which expanded the possibilities and gave organizations the permission to operate a corporate account for these ends, and thus municipalities are catching up to offer this feature. Finally, SnapChat was hardly used at all. 
At this point, it should be stressed that adoption and sophistication are two distinct categories. The fact that municipalities have an account on SM (i.e., adoption) does not tell how they operate their accounts (i.e., sophistication). Therefore, we refine our analysis with descriptive statistics for a range of metadata for every municipal SM account, which maps the degree of SM sophistication. This analysis was executed partially in line with the corresponding overview as provided by Bonsón, Torres, Royo, \& Flores (2012). ${ }^{4}$ Table 2 provides an overview of the presence of Dutch municipalities on Twitter, Facebook, LinkedIn, YouTube, and Instagram. Items highlighted in gray indicate an active presence of the municipality (e.g., launch of the platform, number of followers, and activity), the other items indicate a passive presence (e.g., the amount of followers).

\footnotetext{
${ }^{4}$ The table is different from the corresponding table in Bonsón, Torres, Royo, \& Flores (2012) in two ways:
}

(1) Some items were excluded or interpreted differently. We chose to measure some variables per day if a start date for the account was given, so that municipalities who have been active on a specific platform for over a longer period would not have an advantage over others.

(2) Our interpretation of 'active' and 'passive' presence of a municipality is different in the sense that we consider variables to be 'active' if the municipality can exert direct influence over them, e.g., by posting a tweet or an update on LinkedIn. 'Passive', then, concerns the 'supply side' on the platform over which the municipality does not have direct agency: e.g., the amount of followers, the amount of views. 
*** Please insert Table 2 about here ***

The table shows a great degree of variety that can be seen across all SM platforms. After testing the skewness and kurtosis levels we observed that apart from Account longevity, it appeared that none of the presented items are normally distributed. All of the variables have a positive skew and high positive kurtosis, meaning that the distributions are characterized by a very large share of municipalities with lower numbers compared to only a few municipalities with high numbers. ${ }^{5}$ In many cases, there is a handful of municipalities that are very active, whereas the vast majority is significantly less active.

*** Please insert Figure 1 about here $* * *$

${ }^{5}$ The skewness and kurtosis data for all variables are available upon request. 
Figure 1 shows this, with a steep distribution with a focus on the left side: $69.8 \%$ of all municipalities send out less than two tweets a day on average. Only four municipalities were disproportionately active on Twitter in this respect. ${ }^{6,7}$

It is intuitive to consider population as an important determinant for the skewness of all variables: a larger population necessarily leads to more citizens reaching out, which in turn leads to a greater demand of municipal interaction. The determinants of the degree of SM sophistication will be addressed in greater detail in the next paragraph.

\subsection{Tweet analysis and OLS Regression}

In this section, the sophistication of SM usage and the determinants for e-government adoption are conjoined by means of a further analysis of municipal SM usage in the

\footnotetext{
${ }^{6}$ It should be noted that there were a few recurrent outlying municipalities in our exploration of these data. Primarily these were the four largest Dutch municipalities in 2018: Amsterdam $(855,896$ inhabitants), Rotterdam (638,751 inhabitants), The Hague (531,935 inhabitants), and Utrecht (347,526 inhabitants). However, no municipality was consistently the most active across all items and thus the most significant cause for the skewed distribution.
}

\footnotetext{
${ }^{7}$ Additionally, we wanted to see if municipalities had a comparable online longevity across platforms. In order to do so, we ran Pearson correlations. All of the correlation coefficients for the longevity variables for Twitter, Facebook, and Websites, were positively significant at the 0.01 level (TwitterYouTube $0.339^{* *}$,Twitter-Website $0.200^{* *}$, Youtube-Website, $0.215^{* *}$ ), indicating that municipalities often have the same longevity across platforms
} 
Netherlands. We build on Bonsón, Torres, Royo, \& Flores (2012), who after their overall view looked at which factors promote the level of development of social media tools at a local level. In order to define sophistication of SM usage, we will return to our adaptation of the three-stage e-government framework of Lee \& Kwak (2012). In the first part of this section we develop an argument in which we link Twitter data to our stages model in a variety of ways. After this, we identify socio-economic and institutional factors determining the elaborated sophistication of SM usage and subsequently formulate a regression model.

Foller.me (Kovshenin, 2018) was used for the next part of our analysis, which provided more detailed data on the Twitter usage of Dutch municipalities. First we looked at from which client a Twitter account sent its messages. The client can be described as the 'engine' that is used in order to tweet. It can be argued that three types of usage are to be discerned by means of the three designated stages:

1. Basic Twitter clients. Twitter Web Client: iPhone, Android, and iPad. Usage of these clients indicates that a tweet was sent from a client provided by Twitter itself. This could be considered as the most rudimentary form of e-government: Twitter is used directly through the web engine.

2. Generic Twitter management tools: HootSuite, TweetDeck, and dlvr.it. These are generic applications that allow people and organizations to monitor and overlook their Twitter contacts and interactions. They allow a more multi-layered approach to Twitter usage, as they provide more structure and oversight to the whole of Twitter, and enable easy differentiation between the different goals with which Twitter is employed (such as responding to queries and sending out messages of a general informative nature, regarding a particular topic, or specific \#hashtags). 
3. Specialized SM management tools: OBI4Wan, Coosto, and SIMSite. These clients are supplied by for-profit businesses that developed (social) media monitoring and online customer contact services. We consider the usage of these clients as the most farreaching of the three types of usage, in the sense that they offer comprehensive dashboard functions. These applications are in congruence with the Ubiquitous engagement level of e-government (Lee \& Kwak, 2012): they enable a holistic approach with integrating government information, public engagement methods, SM tools, and government services into one hub, dashboard, or similar. Moreover, as they are paid-for services, usage by municipalities of these clients also indicates that they are willing to invest money and personnel into a further professionalization of their SM usage.

*** Please insert Figure 2 about here ***

Figure 2 shows that the largest part of Dutch municipalities still uses basic Twitter clients: the Twitter Web Client accounts for $83.1 \%$ of all of the accounts, and Twitter for iPhone, Android, and iPad are used by respectively 47.9\%, 24.3\%, and 10.8\%. Specialized tools are also used relatively frequently: $50.3 \%$ of the municipalities use OBI4Wan, $16.4 \%$ use Coosto, and $6.6 \%$ make use of SIMsite. Interestingly, only a relatively small share of the accounts uses generic Twitter management tools - our designated Level 2 of SM sophistication. 14.0\% uses HootSuite, and $11.1 \%$ uses TweetDeck. The image for this item is thus a lot more mixed and equally distributed than was the case with the social media metrics discussed in the previous section. Finally, it should be noted that nearly all municipalities using Level 2- and 
3-engines seem to use a hybrid approach, in which they also still make use of Twitter clients from less sophisticated stages for sending out their tweets.

Next to retracing Twitter clients, Foller.me also makes it possible to gain insight in the last 100 tweets that were sent out by a Twitter account. It analyzes and aggregates a range of aspects associated with these tweets and shows the amount of (1) tweets that were sent as replies to an earlier tweet, (2) tweets that include @ mentions of other accounts, ${ }^{8}(3)$ tweets that use \#hashtags, (4) tweets that are retweets (i.e. reposted messages by others), (5) tweets that include links, and (6) tweets that include media (such as images and videos).

*** Please insert Table 3 about here $* * *$

Table 3 shows the descriptive statistics for these different types of tweets. It shows that tweets with links appear to be used most frequently among municipalities, together with @mentions. These are followed at a greater distance by tweets with \#hashtags, retweets, and replies. Tweets with media on average form less than one tenth of tweets sent out by municipalities. Finally, the same observation as in the previous section can be made regarding skewness: all of the variables show a large peak in the lower levels. Figure 3 serves as another illustration for this.

${ }^{8}$ This is different from the reply in the sense that in a tweet, you can 'mention' the name of a different account, without this having to be in reply to a tweet by that particular account. 
*** Please insert Figure 3 about here ***

What this figure shows is that the amount of replies sent by Dutch municipalities is generally low: $49.7 \%$ of all municipalities 10 or less of their last 100 tweets to a reply to an earlier message.

For the next part, we argue that the different types of tweets can form a further refinement of a municipality's e-government sophistication level. Tanupabrungsun, Hemsley, \& Semaan (2018) distinguished between 'rich tweets' and 'informational tweets'. The former addresses interaction of an account with other accounts, whereas the latter indicates a tweet that is informational of itself, and does not involve interaction with others. Rich content features (e.g., @mentions, retweets and hashtags) are able to reduce ambiguity by enhancing the richness of a tweet's content. Tweets with a @ mention, they argue, are interpreted in the context of addressing someone to specify the recipients. Accordingly, they classify all remaining tweets (plain text or tweets with URLs) as informational. This division between 'rich' and 'informational' tweets can be perceived as a criterion for e-government sophistication. In accordance with the stages of e-government, we argue for the existence of the following tripartite structure:

1. Tweets with links can be considered baseline informational Twitter usage. It is unidirectional, mainly focused around informing and reporting, excluding the possibility to engage in conversation. 
2. Tweets with hashtags, media, @mentions, and retweets already are more focused on not using Twitter as a 'transmission channel', but also in creating the ground conditions and contexts for engagement and interaction.

3. Replies indicate the most sophisticated stage of e-government than just using the medium in order to transmit a particular message. The platform is used in a straightforward, responsive and multidirectional fashion, that is rich in context and engagement level - as the tweets are straightly directed to a particular account or addressee.

\section{Results}

In this section, we expand the argument that the amount of replies sent by a Twitter account forms an indication for the degree of SM adoption and sophistication in a government. With this, we build on recent work (Budding, Faber, \& Gradus, 2018) that sought explanations for the variance in e-service delivery in Dutch municipalities. Earlier literature has defined variables in order to look for determinants of differences in social media usage among municipalities. The definitions for SM adoption are varied: some articles operationalize by means of one SM platform such as Facebook (e.g., Guillamón, Ríos, Gesuele, \& Metallo, 2016) whereas others take into account a constellation of SM platforms in order to formulate an adoption index (e.g., Bonsón, Torres, Royo, \& Flores, 2012; Larsson, 2013; Lidén \& Larsson, 2016; Mossberger, Wu, \& Crawford, 2013). For our regression model, we assessed specifically the usage of Twitter, as the operationalization of Twitter replies is adjusted to our previously elaborated stages model.

We looked at the following variables for our assessment. All of these variables originated in Manoharan's (2013) analysis. The data to support the variables is discussed below. 
1. Socio-economic variables:
a. Population
b. Population density (measured as address density)
c. Percentage of inhabitants in old or young age groups
d. Percentage of people that has followed higher education
e. Presence of ICT businesses

2. Institutional variables:
a. Participation in innovation program
b. Website Longevity
c. Merger

Population, age groups, education, and average income per municipality were included as continuous variables. Presence of ICT businesses consists of the number of registered ICT businesses per 1,000 inhabitants; earlier literature on the Dutch context suggested that ICT businesses operate more efficiently and innovatively when located in higher ICT employment regions (Boschma \& Weterings, 2005). We also included a dummy variable for municipal mergers, sometimes called 'amalgamations'. This variable assesses whether a municipality has been subject to a municipal merger in the previous five years (counted from the year of observation). Time delay should be accounted for before its possible effects can be retraced. Municipal mergers are often aimed at exploiting economies of scale (e.g., Allers \& Geertsema 2016), as well as a chance for municipalities to restructure their operations and to revise business processes, thus providing a quality impulse for public service delivery $(e . g$., Steiner \& Kaiser, 2017). Table 4 shows descriptive statistics of all the assessed variables. 
For the next step in our analysis, the variable 'People in the age group 20-65' is excluded, as it forms the reference group for the equivalent variables. Additionally, some variables (population, population density, higher education, and website longevity) were converted to their natural log form in order to reduce their skewness level. Finally, in order to assess multicollinearity, the variance inflation factor (VIF) was computed for all variables. This assessment did not lead to any possible issues. Table 5 shows the results of the regression model, where the amount of Twitter replies is taken as the dependent variable.

*** Please insert Table 5 about here ***

The table shows that the model is statistically significant. High significance can be observed for a range of variables: of the socio-economic variables, population, population density, a larger presence of people in the age group 20-65, and a larger presence of people with a degree in higher education all were positively significant at the <.01-level. Website longevity was the only positively significant institutional variable. People in the age group older than 65, a municipal merger, participation in an innovation program, and the presence of ICT businesses were not significant. ${ }^{9}$

\footnotetext{
${ }^{9}$ In addition to the regression with the amount of Twitter replies as a dependent variable, we executed an ordered logit regression with the type of Twitter engine. As elaborated in the previous section, this was a variable that fitted our three-stage model for e-government adoption. However, this model
} 


\section{Discussion, conclusion, and future research}

This article discusses the way in which information and interaction is shaped by Dutch municipalities through social media, and the different 'shades' of e-government these different forms entail, in order to facilitate corporate dialog (Bonsón \& Flores, 2011; Bónson, Torres, Royo, \& Flores, 2012). The finding that is consistent throughout is that SM practices, usages, and sophistication among municipalities vary widely.

The first part of this article showed that the presence of municipalities on some SM platforms was near $100 \%$. However, in its active as well as its passive presence a significant variance was observed. Nearly all of the variables were characterized by a few very active municipalities and a majority of scarcely active municipalities. After this, we elaborated that the amount of replies could form an indication for the degree of sophistication of SM usage by municipalities.

We used the replies variable to assess e-government adoption and its determinants, in line with earlier literature (Budding, Faber, \& Gradus, 2018; Manoharan, 2013). We assumed that the amount of replies in a municipality could form an interesting approach for explaining the degree of variance in e-government within Dutch local governments. Our results are in support of earlier literature that finds population a key influencing factor for e-government

showed no significant results. Moreover, we attempted the same type of regression on the basis of a Sophistication Index (cf. Bonsón, Torres, Royo, \& Flores, 2012) for SM adaptation by municipalities, which led to few relevant results. All these additional analyses are available upon request. 
adoption (Andrews \& Boyne, 2009; Guillamón, Ríos, Gesuele, \& Metallo, 2016; Ho, 2002; Moon, 2002; Ruano de la Fuente, 2014) as well as population density; the latter in turn could form an indicator for organizational size (Ruano de la Fuente, 2014). The finding regarding people in the age group 20-65 provides support for earlier findings that it is primarily the working people benefiting from e-government adoption: they could have queries for their municipality regarding various life events, but might have less time to visit the municipal hall during office hours (Budding, Faber, \& Gradus, 2018). Significance regarding higher education are in support of the finding that SM are generally characterized by a larger presence of people with a degree in higher education (Bailey \& Ngwenyama, 2011). To our knowledge, the significant findings regarding website longevity have only been supported by Manoharan's (2013) research. An argument for this could be that it signifies an innovative culture within a municipality: the fact that a website has been an early adopter regarding websites could form an indication that it is in fact willing to invest time, money and personnel in innovative strategies with respect to e-government (cf. Nah \& Saxton, 2013).

This study has some limitations. The data used for the Tweet analysis are metadata, and therefore they do not take into account the actual message of the data, which could entail a different take on the way a municipality engages with its public. It assumes information transmission as a 'lower-level' form of e-government. In practice, this transmission could include queries for information and participation from citizens. Next to this, the fact that the application takes the last 100 tweets, and does not take into account chronology or scope of these tweets, could form a distortion in the dataset that was used. Finally, for the scope of this article we chose to focus primarily on the output side of the municipalities on Twitter, hereby disregarding its representativeness issues. 
The options for future research are manifold. This article took into account socio-economic and institutional variables in order to assess e-government adoption, and did not look into other contextual factors. Future research should take into account the contextual side of egovernment, in addition to the two types of variables presented here. Additionally, most research is focused on the What-question of social media usage by public sector organizations: what type of content is exchanged. To a lesser degree, the How-question is taken into account, which in turn provided the starting point for the present paper. Future research should integrate the What- and How-questions by also analyzing tweet content and paying more attention to the information and the message that is actually conveyed.

\section{Funding}

This research did not receive any specific grant from funding agencies in the public, commercial, or not-for-profit sectors.

\section{Acknowledgements}

We are grateful for comments on earlier versions of this paper we received from Tom Groot and from participants of the 10th EIASM Public Sector Conference in Lund, Sweden, September 2018.

\section{References}

Allers, M. A., \& Geertsema, J. B. (2016). The Effects of Local Government Amalgamation on Public Spending, Taxation, and Service Levels: Evidence from 15 years of Municipal Consolidation. Journal of Regional Science, 56(4): 659-682.

https://doi.org/10.1111/jors.12268 
Andersen, K. V., \& Henriksen, H. Z. (2006). e-Government maturity models: Extension of the Layne and Lee model. Government Information Quarterly, 23(2), 236-248.

https://doi.org/10.1016/j.giq.2005.11.008

Bailey, A., \& Ngwenyama, O. (2011). The challenge of e-participation in the digital city: Exploring generational influences among community telecentre users. Telematics and Informatics, 28(3), 204-214. https://doi.org/10.1016/j.tele.2010.09.004

Bellström, P., Magnusson, M., Pettersson, J. S. \& Thorén, C. (2016). Facebook usage in a local government: A content analysis of page owner posts and user posts. Transforming Government: People, Process and Policy, 10(4), 548-567. https://doi.org/10.1108/TG-12$\underline{2015-0061}$

Benetoli, A., Chen, T. F., Schaefer, M., Chaar, B., \& Aslani, P. (2017). Do pharmacists use social media for patient care?. International Journal of Clinical Pharmacy, 39(2), 364-372. https://doi.org/10.1007/s11096-017-0444-4

Bertot, J. C., Jaeger, P. T., \& Grimes, J. M. (2010). Using ICTs to create a culture of transparency: E-government and social media as openness and anti-corruption tools for societies, Government Information Quarterly, 27(3), 264-71. https://doi.org/10.1016/j.giq.2010.03.001

Bertot, J. C., Jaeger, P. T., \& Hansen, D. (2012). The impact of polices on government social media usage: Issues, challenges, and recommendations. Government Information Quarterly, 29(1): 30-40. https://doi.org/10.1016/j.giq.2011.04.004

Bonsón, E., \& Flores, F. (2011). Social media and corporate dialogue: the response of global financial institutions, Online Information Review, 35(1), 34-49. https://doi.org/10.1108/14684521111113579

Bonsón, E., Royo, S., \& Ratkai, M. (2014). Facebook Practices in Western European Municipalities. An Empirical Analysis of Activity and Citizens' Engagement. Administration \& Society, 49(3), 320-347. https://doi.org/10.1177\%2F0095399714544945 
Bonsón, E., Royo, S., \& Ratkai, M. (2015). Citizens' engagement on local governments FB sites. An empirical analysis: The impact of different media and content types in Western Europe. Government Information Quarterly, 32(1), 52-62. https://doi.org/10.1016/j.giq.2014.11.001

Bonsón, E., Torres, L., Royo, S., \& Flores, F. (2012). Local e-government 2.0: social media and corporate transparency in municipalities. Government Information Quarterly, 29(2), 123-132. https://doi.org/10.1016/j.giq.2011.10.001

Boschma, R. A., \& Weterings, A. B. R. (2005). The effect of regional differences on the performance of software firms in the Netherlands. Journal of Economic Geography, 5(5), 567-588, https://doi.org/10.1093/jeg/lbh074

Budding, T., Faber, A. S. C., \& Gradus, R. H. J. M. (2018). Assessing electronic service delivery in municipalities: determinants and financial consequences of e-government implementation. Local Government Studies, 44(5), 697-718. https://doi.org/10.1080/03003930.2018.1473768

Chang, W.-L., Yuan, S.-T. \& Li, E. Y. (2009). iCare home portal: An extended model of quality aging e-services. Communications of the ACM, 52(11), 118-124. https://doi.org/10.1145/1592761.1592790

Chun, S., Shulman, S., Sandoval, R., \& Hovy, E. (2010). Government 2.0: Making connections between citizens, data and government. Information Polity, 15(1, 2), 1-9. https://doi.org/0.3233/IP-2010-0205

Dunleavy, P., Margetts, H., Bastow, S., \& Tinkler, J. (2005). New Public Management Is DeadLong Live Digital-Era Governance. Journal of Public Administration Research and Theory, 16, 467-494. https://doi.org/10.1093/acprof:oso/9780199296194.003.0009

Gao, X., \& Lee, J. (2017). E-government services and social media adoption: Experience of small local governments in Nebraska state. Government Information Quarterly 34(4), 627-634. https://doi.org/10.1016/j.giq.2017.09.005 
Gottschalk, P. (2009). Maturity levels for interoperability in digital government. Government Information Quarterly, 26(1), 75-81. https://doi.org/10.1016/j.giq.2008.03.003

Grajales III, F. J., Sheps, S., Ho, K., Novak-Lauscher, H., \& Eysenbach, G. (2014). Social media: a review and tutorial of applications in medicine and health care. Journal of medical Internet research, 16(2). https://doi.org/10.2196/jmir.2912

Grimmelikhuijsen, S. G., \& Meijer, A. J. (2015). Does Twitter Increase Perceived Police Legitimacy? Public Administration Review, 75(4), 598-607. https://doi.org/10.1111/puar.12378

Guillamón, M.-D., Ríos, A.-M., Gesuele, B., \& Metallo, C. (2016). Factors influencing social media use in local governments: The case of Italy and Spain. Government Information Quarterly, 33(1), 460-471. https://doi.org/10.1016/j.giq.2016.06.005

Harrison, T. M., Guerrero, S., Burke, G. B., Cook, M., Cresswell, A., Helbig, N., . . Pardo, T. (2012). Open government and e-government: Democratic challenges from a public value perspective, Information Polity, 17(2), 83-97. https://doi.org/10.3233/IP-2012-0269

Hartholt, S. (2017). Juridisch Probleem voor WhatsAppende Gemeenten, Binnenlands Bestuur, 5 September, online: https://www.binnenlandsbestuur.nl/bestuur-enorganisatie/nieuws/juridisch-probleem-voor-whatsappende-gemeenten.9570410.lynkx, last accessed on 30 July 2018.

Ho, A. T. (2002). Reinventing Local Governments and the E-Government Initiative. Public Administration Review, 62(4), 434-444. https://doi.org/10.1111/0033-3352.00197

Hofmann, S., Beverungen, D., Räckers, M., \& Becker, J. (2013). What makes local Governments' online communications successful? Insights from a multi-method analysis of Facebook. Government Information Quarterly, 30(4), 387-396. https://doi.org/10.1016/j.giq.2013.05.013 
Kaplan, A. M., \& Haenlein, M. (2010). Users of the world, unite! The challenges and opportunities of social media. Business Horizons, 53(1), 59-68. https://doi.org/10.1016/j.bushor.2009.09.003

Klang, M., \& Nolin, J. (2011). Disciplining social media: An analysis of social media policies in 26 Swedish municipalities, First Monday, 16(8). https://doi.org/10.5210/fm.v16i8.3490

Kovshenin, K. (2018). Foller.me. Application that uses Twitter API, Bootstrap and WordPress. Online: https://foller.me/, last accessed 30 July 2018.

Larsson, A. O. (2013). Bringing it all back home? Social media practices by Swedish municipalities. European Journal of Communication, 28(6), 681-695. https://doi.org/10.1177\%2F0267323113502277

Layne, K., \& Lee, J. (2001). Developing fully functional E-government: A four stage model. Government Information Quarterly, 18(2), 122-136. https://doi.org/10.1016/s0740$\underline{624 x(01) 00066-1}$

Lidén, G., \& Larsson, A. O. (2016). From 1.0 to 2.0: Swedish municipalities online, Journal of Information Technology \& Politics, 13(4), 339-351. https://doi.org/10.1080/19331681.2016.1169242

Linders, D. (2012). Towards open development: Leveraging open data to improve the planning and coordination of international aid. Government Information Quarterly 30(4), 426-434. http://doi.org/10.1016/j.giq.2012.06.003

Liu, S. M., \& Kim, Y. (2018). Special issue on internet plus government: New opportunities to solve public problems? Government Information Quarterly, 23(2), 236-248. https://doi.org/10.1016/j.giq.2018.01.004

Manoharan, A. (2013). A Study of the Determinants of County E-Government in the United States. American Review of Public Administration, 43(2), 159-178. https://doi.org/10.1177/0275074012437876 
Mergel, I. (2013). A framework for interpreting social media interactions in the public sector, Government Information Quarterly, 30(4), 327-34. https://doi.org/10.1016/j.giq.2013.05.015

Mergel, I. (2016). social media institutionalization in the U. S. federal government, Government Information Quarterly, 33(1), 142-48. https://doi.org/10.1016/j.giq.2015.09.002

Molinari, F., \& Ferro, E. (2009). Framing Web 2.0 in the process of public sector innovation: Going down the participation ladder. European Journal of ePractice, 9(1), 20-34.

Moon, M. J. (2002). The evolution of e-government among municipalities: Rhetoric or reality? Public Administration Review, 62(4), 424-433. https://doi.org/10.1111/0033-3352.00196

Mossberger, K., Wu, Y., \& Crawford, J. (2013). Connecting citizens and local governments? Social media and interactivity in major U.S. cities. Government Information Quarterly, 30(4), 351358. https://doi.org/10.1016/j.giq.2013.05.016

Nah, S., \& Saxton, G. D. (2013). Modeling the Adoption and Use of Social Media by Nonprofit Organizations. New Media \& Society, 15(2): 294-313. https://doi.org/10.1177/1461444812452411

Newcom Research \& Consultancy. (2018). social media onderzoek 2018. Research Report. Amsterdam: Newcom Research \& Consultancy, 29 January.

Ruano de la Fuente, J. (2014). E-Government Strategies in Spanish Local Governments. Local Government Studies, 40(4), 600-620. https://doi.org/10.1080/03003930.2013.787414

Sandoval-Almazán, R., \& Kavanaugh, A. L. (2018). Introduction to the special issue on social media and government. First Monday, 23(4). https://doi.org/10.5210/fm.v23i4.8317

Statistics Netherlands (Centraal Bureau voor de Statistiek). (2017). ICT, Kennis en economie. Report, The Hague/Heerlen.

Steiner, R., \& Kaiser, C. (2017). Effects of Amalgamations: Evidence from Swiss Municipalities. Public Management Review, 19(2): 232-252. https://doi.org/10.1080/14719037.2016.1153704 
Tanupabrungsun, S., Hemsley, J., \& Semaan, B. (2018). Information affordances: Studying the information processing activities of the core Occupy actors on Twitter. First Monday, 23(2). https://doi.org/10.5210/fm.v23i2.7888

Valdés, G., Solar, M., Astudillo, H., Iribarren, M., Concha, G., \& Visconti, M. (2011). Conception, development and implementation of an e-Government maturity model in public agencies. Government Information Quarterly, 28(2), 176-187.

https://doi.org/10.1016/j.giq.2010.04.007

VNG Realisatie. (2018). Waarstaatjegemeente.nl, online: https://waarstaatjegemeente.nl/, last accessed on 26 June 2018.

Von Hoffen, M. Hagge, M., Betzing, J. H., \& Chasin, F. (2018). Leveraging social media to gain insights into service delivery: a study on Airbnb. Information Systems and e-Business Management, 16(2), 247-269. https://doi.org/10.1007/s10257-017-0358-7

Zheng, L., \& Zheng, T. (2014). Innovation through social media in the public sector: Information and interactions. Government Information Quarterly, 31(S1), S106-S117. https://doi.org/10.1016/j.giq.2014.01.011 


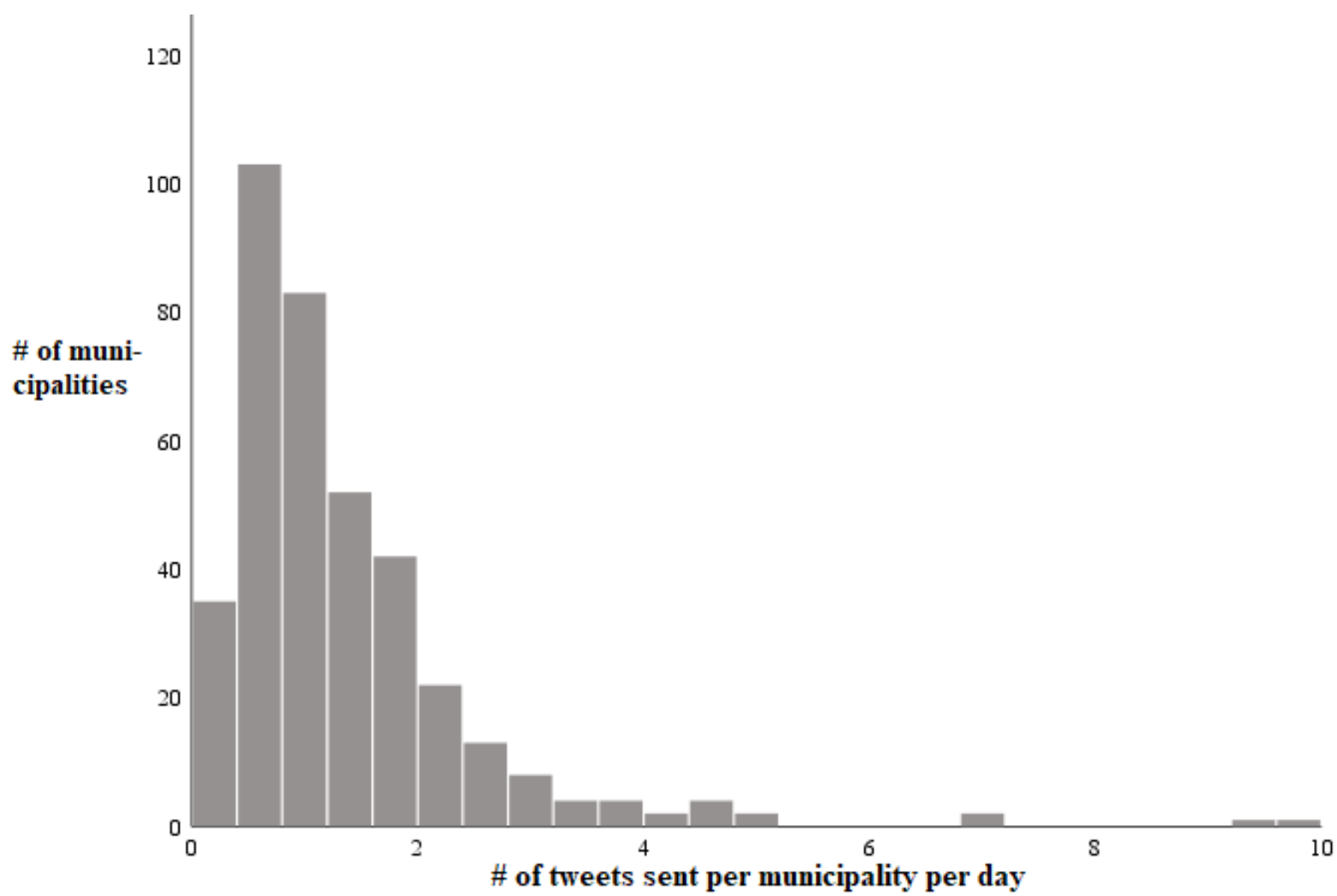

Fig. 1. Histogram of Tweets per day. 


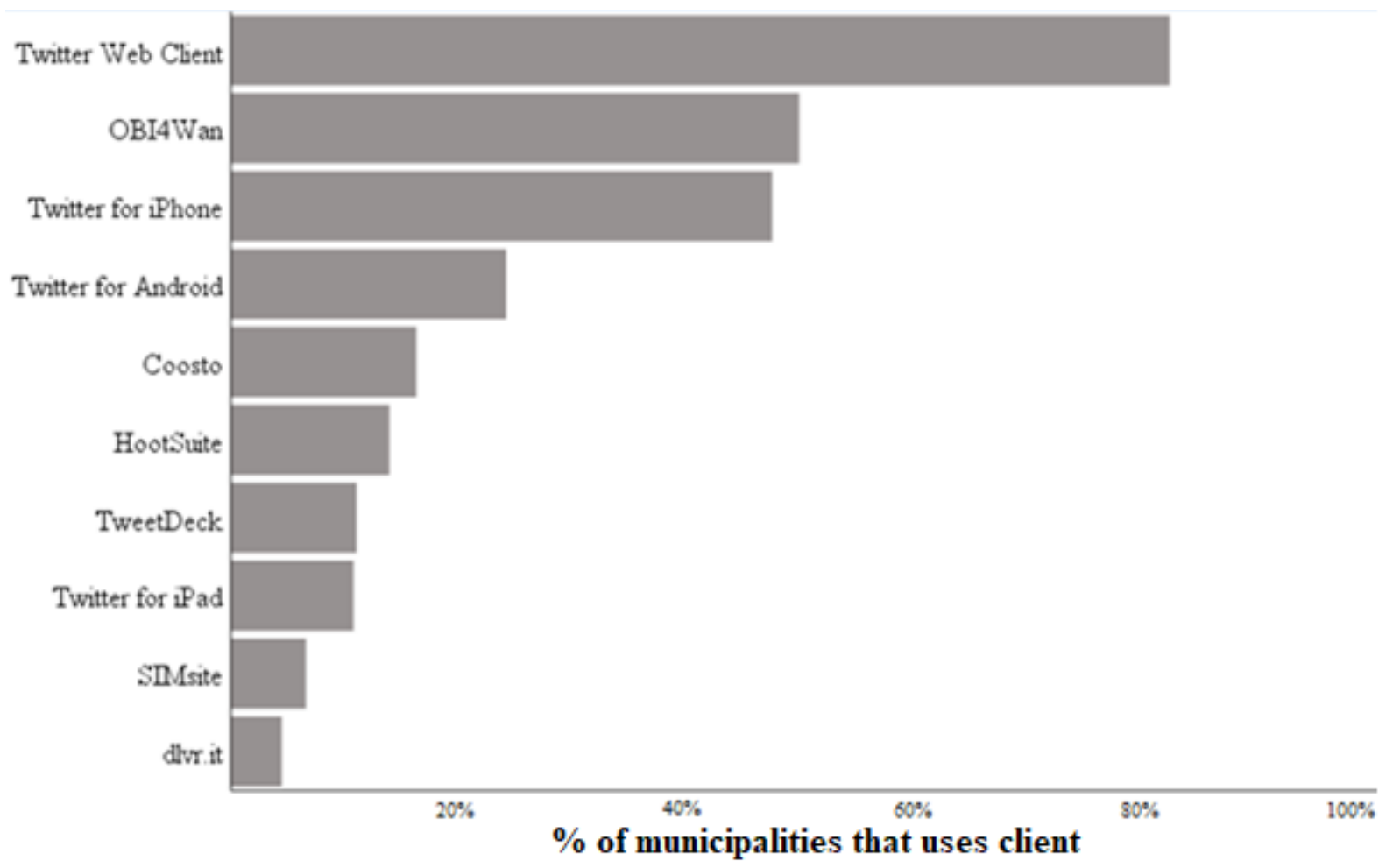

Fig. 2. Twitter clients usage by municipalities, in percentage. 


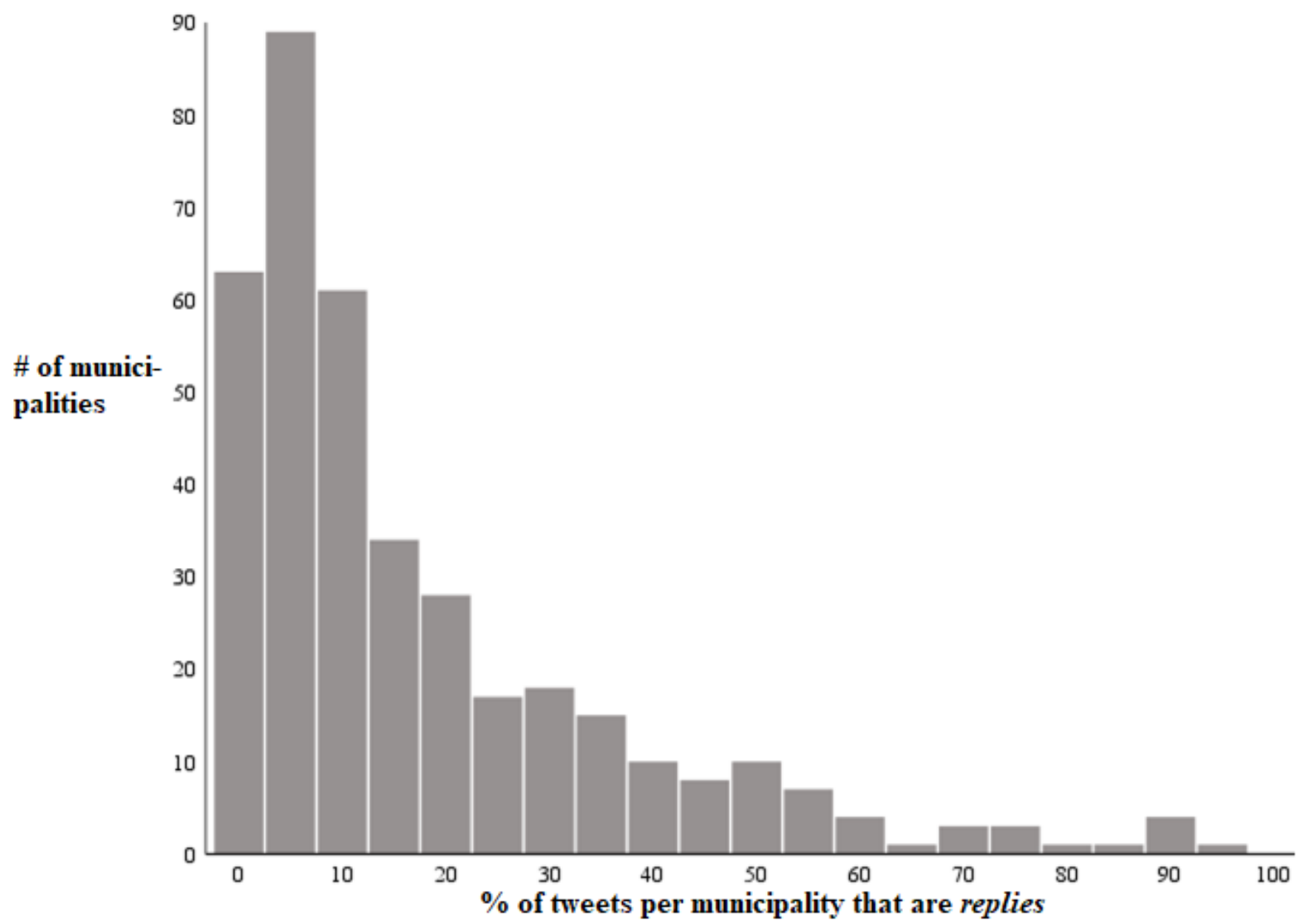

Fig. 3. Histogram of replies by a municipality account, in percentage. 
Table 1

Social media accounts by Dutch municipalities.

\begin{tabular}{|c|c|}
\hline Platform & Municipal account \\
\hline Twitter & $99 \%$ \\
\hline Facebook & $97 \%$ \\
\hline LinkedIn & $97 \%$ \\
\hline YouTube & $89 \%$ \\
\hline Instagram & $67 \%$ \\
\hline WhatsApp & $37 \%$ \\
\hline Snapchat & $1 \%$ \\
\hline
\end{tabular}


Table 2

Dutch municipalities and social media sophistication.

\begin{tabular}{|c|c|c|c|c|c|}
\hline & Social media metrics & Mean & S. D. & Min & Max \\
\hline Twitter & Account longevity & 909.68 & 408.863 & 0 & 3379 \\
\hline \multirow{4}{*}{$(\mathrm{N}=378)$} & Tweets per day & 1.34 & 1.16 & 0.05 & 9.96 \\
\hline & Following & 511.93 & 994.14 & 0 & 10,605 \\
\hline & Likes & 217.84 & 578.51 & 0 & 6,870 \\
\hline & Followers & $5,622.09$ & $22,254.11$ & 163 & 412,168 \\
\hline Facebook & Likes $^{10}$ & $3,305.08$ & $5,323.25$ & 15 & 65,885 \\
\hline$(\mathrm{N}=370)$ & Followers & $3,358.02$ & $5,368.86$ & 15 & 66,665 \\
\hline \multicolumn{6}{|l|}{ LinkedIn } \\
\hline \multirow{2}{*}{$(\mathrm{N}=370)$} & Updates & 17.61 & 39.61 & 0 & 405 \\
\hline & Followers & $1,900.51$ & 3452.52 & 0 & 36,639 \\
\hline \multirow[t]{2}{*}{ YouTube } & Account longevity & 2051.60 & 925.421 & 0 & 4138 \\
\hline & Subscribers & 39.37 & 99.51 & 0 & 1,461 \\
\hline
\end{tabular}

${ }^{10}$ A 'like' has a different meaning for Twitter and Facebook. On Twitter, an account can 'like' another account's tweet, whereas on Facebook a 'like' means that the account has been 'liked' by another account. 


\begin{tabular}{|c|c|c|c|c|c|}
\hline$(\mathrm{N}=339)$ & Video views per day & 11.07 & 26.36 & 0.01 & 351.61 \\
\hline Instagram & Posts & 90.09 & 174.49 & 0 & 1650 \\
\hline \multirow{2}{*}{$(\mathrm{N}=257)$} & Following & 151.67 & 511.89 & 0 & 7,494 \\
\hline & Followers & 664.36 & $1,996.12$ & 0 & 23,300 \\
\hline & & & & Active & Passive \\
\hline
\end{tabular}


Table 3

Tweet Analysis: descriptive statistics.

\begin{tabular}{lcccc}
\hline & Mean & S. D. Min & Max \\
\hline Tweets with links & 67.5 & 15.2 & 20.0 & 100.0 \\
Tweets with @ mentions & 40.9 & 21.9 & 1.0 & 100.0 \\
Tweets with \#hashtags & 19.6 & 15.1 & 0.0 & 85.0 \\
Tweets with media & 9.6 & 9.3 & 0.0 & 75.0 \\
Retweets & 19.0 & 16.0 & 0.0 & 96.0 \\
Replies & 17.6 & 19.1 & 0.0 & 93.0 \\
\hline
\end{tabular}


Table 4

Descriptive statistics.

\begin{tabular}{|c|c|c|c|c|c|}
\hline & & Mean & S. D. & Min & Max \\
\hline Socio-economic & Population & 45,221 & 69,680 & 933 & 855,896 \\
\hline \multirow[t]{6}{*}{ variables } & Population density & 840.23 & $1,005.52$ & 25.00 & $6,347.00$ \\
\hline & People in the age group 0-20 & 22.57 & 2.47 & 16.20 & 37.60 \\
\hline & People in the age group 20-65 & 57.03 & 2.61 & 47.50 & 69.00 \\
\hline & People in the age group 65+ & 20.40 & 3.17 & 9.00 & 30.80 \\
\hline & Higher Education & 22.64 & 7.36 & 8.00 & 53.00 \\
\hline & ICT businesses & 3.73 & 1.70 & 1.09 & 13.83 \\
\hline \multirow{4}{*}{$\begin{array}{l}\text { Institutional } \\
\text { variables }\end{array}$} & Participation in Program & 0.34 & 0.47 & 0.00 & 1.00 \\
\hline & (dummy) & & & & \\
\hline & Website Longevity & 1661.44 & 612.65 & 0.00 & 4088.00 \\
\hline & Merger (dummy) & 0.06 & 0.24 & 0.00 & 1.00 \\
\hline
\end{tabular}


Table 5

OLS Regression of factors influencing amount of Twitter replies.

Standardized $\beta$

\begin{tabular}{|c|c|c|}
\hline & (Constant) & -6.688 \\
\hline \multirow{6}{*}{ Socio-economic } & Population (Ln) & $0.510 * * *$ \\
\hline & Population density (Ln) & $0.136 * * *$ \\
\hline & People in the age group $20-65$ & $0.134 * * *$ \\
\hline & People in the age group 65+ & -0.051 \\
\hline & Higher Education (Ln) & $0.209 * * *$ \\
\hline & ICT businesses & $0.092 * * *$ \\
\hline \multirow{2}{*}{ Institutional } & Participation in Program & 0.046 \\
\hline & Website Longevity (Ln) & $0.091 * *$ \\
\hline variables & Merger & 0.001 \\
\hline & Adjusted R2 & $0.585 * * *$ \\
\hline
\end{tabular}

$*<0.1 * *<0.05 * * *<0.01$

Dependent variable: Twitter replies 
Bram Faber is a PhD student at the Zijlstra Center for Public Control, Governance and Leadership, Vrije Universiteit Amsterdam, the Netherlands. His research interests include innovation in public accountability and uses of ICT in public sector reporting and service delivery.

Tjerk Budding is program director of the postgraduate program for certified public controllers at the School of Business and Economics, Vrije Universiteit Amsterdam, the Netherlands. His research interests include e-government, management accounting and control, and financial accounting.

Raymond Gradus is Professor of Public Economics and Administration at the School of Business and Economics, Vrije Universiteit Amsterdam, the Netherlands. His research interests include public administration, local government, environmental policy and social security. 